\title{
OUT OF BORDERS FOR RADICAL GYNECOLOGIC SURGERY
}

doi: 10.2478/rojost-2018-0014

\section{P. Brătilă $\breve{1,2}^{1,}$ E. Brătilă $\breve{2,3}^{2}$}

1"Regina Maria" Private Clinic, Gynecology Department, Euroclinic Hospital, Bucharest, Romania

${ }^{2}$ Department of Obstetrics and Gynaecology, "Carol Davila" University of Medicine and Pharmacy,

Bucharest, Romania

3"Prof. Dr. Panait Sârbu" Clinical Hospital of Obstetrics and Gynaecology, Bucharest, Romania

Advances in several medical disciplines have resulted in greatly improved outcome and reduced morbidity and mortality in the management of complex gynecologic tumors. Early reports of central pelvic exenteration were discouraging and associated with high mortality (28\%) and major complications (100\%). Preoperative medical assessment, expert anesthesia, and postoperative intensive care have reduced perioperative mortality to less than $5 \%$.

For patients with recurrent cervical and endometrial cancer, who already had surgery, and for a minority of primary or recurrent sarcomas without distance metastases, the contemporaneous surgery offers a chance by bone extended resections.

Keywords: gynecologic cancer, uterine sarcoma, endometrial cancer, cervical cancer 